\title{
Use of Interactive Online Textbook for Teaching Online Engineering Course - A Case Study
}

\author{
Priyanka Patki ${ }^{1 \mathrm{a}}$, Feiyan Yu ${ }^{1 \mathrm{~b}}$, Anil Kulkarni ${ }^{1 \mathrm{c}}$ \\ ${ }^{1}$ Department of Mechanical Engineering, The Pennsylvania State University, University Park, Pennsylvania 16802, United \\ State of America \\ ${ }^{\mathrm{a} p a p} 185 @$ psu.edu \\ bfwy5031@psu.edu \\ cakk@psu.edu
}

\begin{abstract}
In this paper, we present a case study for the use of an interactive online textbook (online text) for the purpose of conducting an online course at The Pennsylvania State University (Penn State). The online text and associated software - McGraw Hill Connect, provides an excellent electronic framework for conducting all the homework assignment, quizzes, interactive reading assignments as well as exams online. Conducting an entire online course on such an electronic platform is an innovative idea, and such an experience has not been documented before. Various features in the online text enable the instructor to design the assignments to ensure better understanding of the course material. Similarly, the quizzes and exams can be set in such a way that the chances of cheating and copying can be reduced even in the absence of proctoring. This paper discusses how various features in the online text software have been effectively employed for the purpose of setting up and grading the assignments, quizzes and exams, and efficiently teaching the online course. The most interesting aspect of our course is that in spite of being a completely online course, various features of the online text software have been implemented, that it would closely simulate quizzes, exams etc. as conducted in an in-class course, and student-instructor interactions as would occur in a typical inperson meeting during office hours. Finally, student feedback related to their experience with the software is reported and analysed.
\end{abstract}

Keywords: Interactive online text, McGraw Hill Connect

\section{Introduction}

Online learning can prove to be an extremely effective and

\section{Corresponding Author}

Anil K Kulkarni, Department of Mechanical Engineering, The Pennsylvania State University, University Park, PA 16802 akk@psu.edu

efficient way of educating large number of undergraduate students, especially since it can offer high quality education to non-resident students. While the less technical streams have extensively employed online learning, it has not seen so much popularity in engineering. This can be due to the highly technical and problem-oriented nature of the materials, and because of less inclination of the stream in general towards change from the tradition teaching-learning techniques [1]. However, it has been observed that engineering education can also be effectively provided to non-resident students $[1,2]$. Towards this end, it is important to develop new strategies which would enable effective delivery of the highly technical engineering courses.

In this context, use of online text software packages such as 'McGraw-Hill Connect' (or simply, Connect) for online courses can become an important asset for instructors and students. We discuss the implementation of the e-book software for the textbook, [3] for the online course 'ME 201' offered by the Mechanical Engineering department for undergraduate students pursuing non-mechanical engineering majors at Penn State and students from other universities for whom the course is approved. The word online text can have two main connotations, the first being simply a digital version (or PDF) of the paper book, while the other being a digital (many-a-times interactive) version of the paper book, along with other course materials such as online assignments, quizzes and exams, automatic grading features etc., which can potentially enhance the online teaching-learning experience. The word online text has been used in the latter context in this paper. While analysis of student preferences with regards to the digital version of the textbook as against printed textbooks has been performed previously (cf. e.g. [4], [5], [6]), such literature is not available for the use of electronic book software for the conducting an online course.

Goodson et al., [7], observed that homework assignments with solutions and chapter guides, along with a clear syllabus 
and outline (or a course calendar) benefit online learners. In order to achieve this objective, we use an approach involving integration of the online text with the course management software, Canvas. A part of the course is taught based on the online text. The other part of the course includes the use of Canvas, which hosts video lectures, lecture notes, handouts, grades, schedules, syllabus, and extensive additional information on how the course is conducted. The entire structure of the course is designed before the commencement of the course. Video lectures as well as assignments are assigned to the students on a weekly basis. Owing to the highly technical nature of the course, we also increase student engagement by using clicker and embedded questions $[8,9]$. We also assign what are known as virtual laboratory experiments to further deepen students' understanding of the subject matter. Moreover, as observed in [10], it is essential to allot additional time and effort to ensure understanding of technical intricacies of the subject matter. Thus, regular online and in-person office hours along with revision sessions are conducted in which student difficulties can be addressed. Moreover, as discussed in detail in the following sections, the reading assignments and homework assignments on Connect are designed in such a way, that it almost simulates the student-instructor interactions as would occur in an in-person discussion session. The inclusion of embedded questions and virtual laboratories can be very time-wise and technically intensive for the instructor. On the other hand, the use of an online text can simplify the course designing process significantly, and can be used as a standalone online course delivery framework. This paper focuses on the use of the software Connect for the online course.

Online course delivery is not a novel idea. However, the use of electronic book-software like Connect for conducting an entire online course is an innovative technique of increasing student engagement in the course, and there is a lack of literature providing insights into this new technique of online course delivery. The true novelty of Connect is that it simulates, to a great extent the student-instructor interactions that would typically occur only in an in-class course, which is very difficult to otherwise achieve in an online course. Few examples of this include:

- $\quad$ Reading assignments: These are assigned to students through Connect every week. Students are asked to read a portion of the text on Connect, and objective type questions are posed by the software intermittently, to test the student's understanding of the material he/she has just read. If a student is unable to answer the question correctly, the software guides the student to the text within the book, where the related concept is discussed. Then the student attempts a similar question and so on.. This simulates a typical discussion between a student and instructor: when the student asks the teacher a doubt, most of the times, the instructor simply guides the student towards the portion of the text in which the concept is explained. Thus, the instructor helps the student understand the concept, rather than giving away the answer to the question asked.

- Prescribing online homework assignments: Similarly, Connect provides an option to the instructors to provide 'hints' for numerical homework or quiz problems, through which the relevant concept is highlighted. This is again like an instructor guiding the student to read a concept from a book if the student comes to the instructor with a doubt in a numerical homework problem.

- $\quad$ Conducting quizzes and exams: In order to avoid cheating or copying in in-class exams and quizzes, sometimes instructors create two sets of question papers, with either totally different problems or by having the same questions, with different numerical input values. Connect has the capacity to simulate this, in an automated way, for online quizzes and exams. Connect contains a huge bank of numerical 'algorithmic questions': the problem wording is the same, however, the numerical values of data are different for different students. Moreover, the instructor can scramble questions, so that the order of questions appearing for different students is different. Finally, the instructor can also create a big 'pool' of questions, from which questions are randomly drawn. These strategies can prove to be very effective to ensure minimum cheating and copying for online exams, even without any physical invigilation as in the inclass exams.

The following sections discuss in detail how these strategies were implemented for our online course. An online course which is conducted completely using an electronic book is a new experience for an overwhelming majority of students. We thus collected student opinions on their experiences with the electronic book as against the traditional classes.

The features of Connect, which make it an effective tool for conducting online courses, have been discussed in detail in the following section. The next section talks about the student feedback we have received regarding the use of the electronic book. The final section summarizes our observations and experience related to the online text platform usage.

\section{Setting-up the Software for the Online Course}

The course is setup on two online portals, the Penn Statestandard learning management system (LMS) Canvas and the McGraw-Hill interactive online textbook platform, Connect.

The normal procedure for students was as follows: after familiarizing with the syllabus and introductory videos, every week the students watched typically three video lectures posted on Canvas, used the lecture notes posed as pdf files as necessary and referred to the handouts posted. Simultaneously, they used the Connect portal on Internet and engaged with it comprehensively, as explained in this paper. The online text presented through the Connect platform is essentially an electronic version of the book, with numerous added features. It has a self-contained roster, and the instructor and teaching assistants (TA)s can monitor the student activities through this interface. Student data can be downloaded at any point during the course.

\section{A. Setting Up the Online Course}

The first step for setting up the course on Connect was to visit the McGraw Hill Connect website: https://connect.mheducation.com, and create a login. Then 
the required online text for the course, [1], was selected. A unique registration link was generated for the course, which was then shared with the students in the class, and the students registered for the course by creating a login and registering for the course using the link. The instructor has access to the student roster at all times, which contains details about the student name, email address and date of registration. Special provisions in terms of allotment of extra quiz and exam time are often required for students with learning disability in accordance with the policy at Penn State. Such extensions were also applied for all exams and quizzes through the roster. Often, students require to take a particular quiz or exam at a different time than the time slot allotted to the rest of the class, due to clash of timing with other course exams etc. Extensions or exceptions in such situations can be easily given through the settings of a particular quiz or exam. The course section thus created, along with all the assignments, quizzes etc. can also be exported to another account via the share or copy options, so that the course material can be made available for another course or instructor. The use of various features of Connect for our course are now discussed.

\section{B. General Policies and Settings for Assignments}

Quizzes, homework assignments and exams are all set using just one interface within the software. The common setup page for all assignments is shown in Fig. 1. The type of assignment (homework/quiz/exam) can be chosen here. For our course, the default settings for all the quizzes, exams and homework assignments were set initially, so that the policies are applied uniformly to all the assignments in that particular group. The name of the assignment, start and end date can be set at this interface. Also, we can set whether late submissions are allowed or not, if allowed, will there be a penalty for late submissions etc. Student instructions, if any, can be set at this interface as well. The specific details of settings used for specific assignment types are given in the following subsections in the paper.

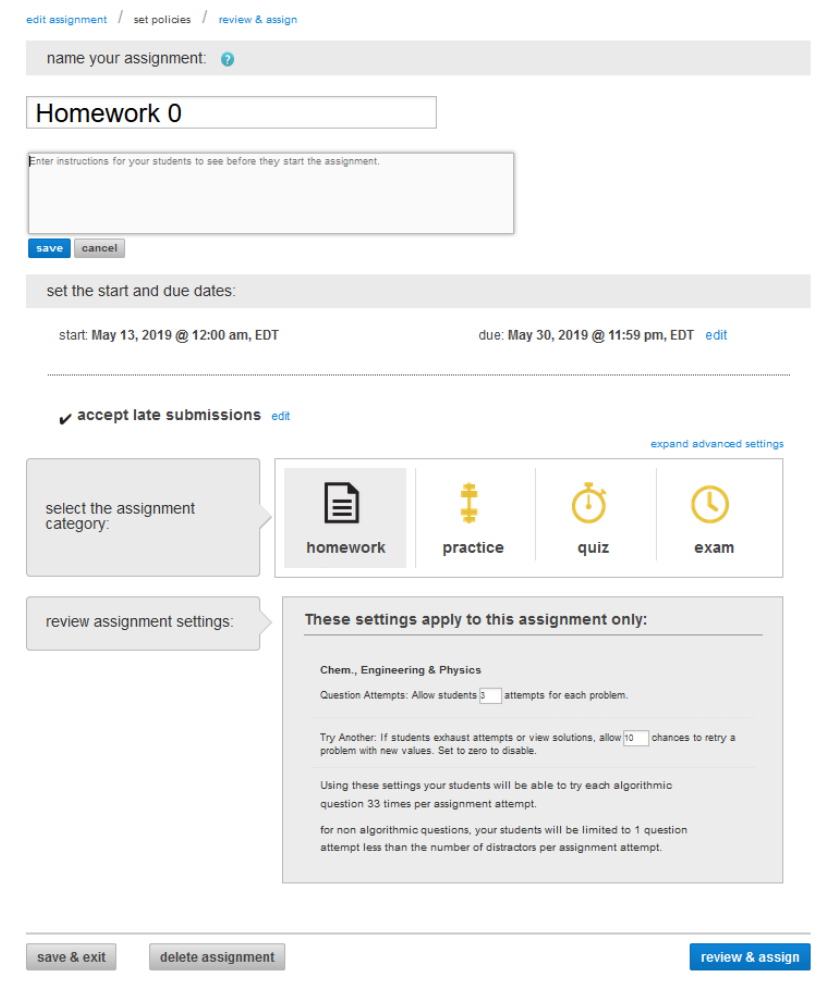

Fig. 1 Main assignment setup interface for all assignments

For all the assignments, questions were either chosen from a big pool of questions provided by the publishers, or were created by the instructor and teaching assistants. Several types of questions were set, such as multiple choice, match the choices, and fill in the blanks primarily for quizzes. Detailed free-response answer type worksheet questions were setup for the homework assignments. The online text software also gives an option of creating pools of several questions from which a fixed number of questions are randomly drawn for every student. The order of appearance of questions can be scrambled, so that different questions appear in a different order for all the students. For questions involving multiple choice questions, there is an additional option of scrambling the options as well. We also used what are known as 'algorithmic questions', in which numerical inputs given in the questions are varied for all students.

Use of these settings for questions in assignments makes it harder for students to cheat or copy from others, and thus helps in indirectly proctoring the students. The software grades questions by itself. For questions from within the online text question bank, the answers are graded automatically based on the inbuilt answer key. For questions which are set by the instructor, answer keys need to be provided. For our course, we employed this automatic grading facility of the online text. In case any discrepancies related to the solutions were found, those questions were manually graded for individual students or uniform points were assigned to the entire class in case there was a genuine flaw in the question itself. Moreover, an important part of the course curriculum is reading assignments, which 
are especially essential for any online course to ensure proper understanding of the course material. The use of the online text software for setting such reading assignments is also discussed later in the paper.

The online text provides with several options which can be conveniently chosen according to the exam requirements. Various available options for settings are shown in Fig. 2a2e. Instead of presenting detailed discussion on all the available options, the relevant options are discussed later while discussing the specific assignment types.

\begin{tabular}{|l|l|}
\hline settings & \\
\hline basic & $\square$ time limit $\square$ minutes \\
\hline allow printing \\
attempts & $\square$ scramble the questions ? \\
\hline tolerances & give credit for completion ? $?$ \\
\hline resources & Students automatically receive full credit on every \\
\hline feedback & \\
& \\
\end{tabular}

Fig. 2a Basic settings for the assignments

\begin{tabular}{|c|c|c|}
\hline settings & & \\
\hline \multirow[t]{2}{*}{ basic } & \multicolumn{2}{|r|}{ see example? } \\
\hline & Assignment attempts allowed: unlimited & $\checkmark$ \\
\hline attempts & $\begin{array}{l}\text { On each new attempt, students will: } \\
\text { start over }\end{array}$ & \\
\hline tolerances & revise the previous attempt & \\
\hline \multirow[t]{2}{*}{ resources } & $\begin{array}{l}\square \text { For each attempt after the first, deduct } 0 \\
\text { from the attempt score }\end{array}$ & \\
\hline & $\square$ compound the deduction for each att & $\mathrm{mpt}$ \\
\hline \multirow[t]{2}{*}{ feedback } & $\square$ allow for study attempts & \\
\hline & $\begin{array}{l}\text { After the due date, this assignment will be avail } \\
\text { without affecting their grade }\end{array}$ & le to students \\
\hline
\end{tabular}

Fig. 2b Settings related to attempts: number of attempts; for multiple attempt assignments whether the answers submitted for the previous attempts are retained in the next one or students starts afresh for every new attempt; whether successive attempts are to be penalized

\begin{tabular}{l|l} 
settings & $\begin{array}{l}\text { global answer tolerance setting: } 5 \% \text {. } \% \\
\text { For example: Using } 2 \% \text {, if the answer is 100, then answers } \\
\text { in the range of } 98-102 \text { will be accepted }\end{array}$ \\
\hline attempts & \\
tolerances & \\
\hline resources & \\
\hline feedback &
\end{tabular}

Fig. 2c Settings related to tolerance for problems requiring numerical value as feedback. Typically the tolerance value is set to $10 \%$ for all numerical problems

\begin{tabular}{|c|c|}
\hline settings & \\
\hline \multirow{3}{*}{$\begin{array}{l}\text { basic } \\
\text { attempts }\end{array}$} & reference types? See example \\
\hline & $\square$ question title \\
\hline & $\square$ external links \\
\hline tolerances & assistance types? See example \\
\hline \multirow{2}{*}{ resources } & $\square$ eBook \& resources \\
\hline & $\square$ hints \\
\hline \multirow[t]{7}{*}{ feedback } & $\square$ check my work \\
\hline & $\begin{array}{l}\text { Students may check if their answers are correct } \\
\text { before submitting. }\end{array}$ \\
\hline & $\begin{array}{l}\square \text { show solutions and answers } \\
\text { Students may see the formula and correct answer (if } \\
\text { available). }\end{array}$ \\
\hline & $\begin{array}{l}\square \text { show guided solutions and answers } \\
\text { Students may see a step-by-step tutorial on how to solve } \\
\text { questions of that type, and the correct answer (if } \\
\text { available). }\end{array}$ \\
\hline & $\begin{array}{l}\square \text { practice questions } \\
\text { Students may complete unscored versions of the } \\
\text { questions. }\end{array}$ \\
\hline & $\square$ ask the instructor \\
\hline & $\begin{array}{l}\text { Students may message the instructor about a } \\
\text { specific question. }\end{array}$ \\
\hline
\end{tabular}

Fig. 2d Resources for the assignment: typically no assistance is permitted, except for access to online text for homework assignments

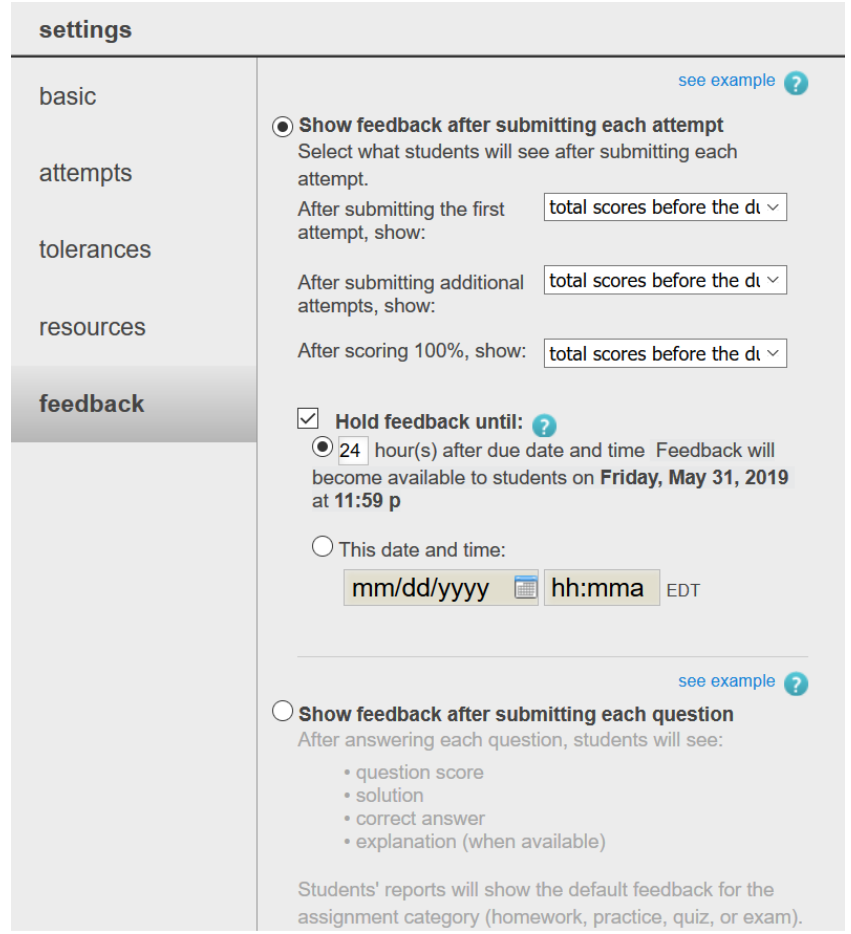

Fig. 2e Feedback of the assignments: For all quizzes and homework assignments, feedback (detailed solutions) and correct/wrong answer for each question is provided 24 hours after the submission deadline. For quizzes as well as homework assignments, students see their total scores after every attempt 


\section{1) Textbook and Reading Assignments:}

The online text in itself is distributed in chapters and sections, which are hyperlinked for easy navigation. Important concepts in the text are highlighted so that students can refer these for a quick revision. Reading assignments were set up via the 'LearnSmart' module in the online text. Certain sections of the book were assigned to the students to read within a particular a week as reading assignments.

The online text has embedded questions within the text at random locations. In order to mark a reading assignment as 'complete', the students are not only expected to read the assigned text, but also attempt all the embedded practice problems correctly. Fig. 3 and 4 show a typical electronic text interface and an example of an embedded practice problem.

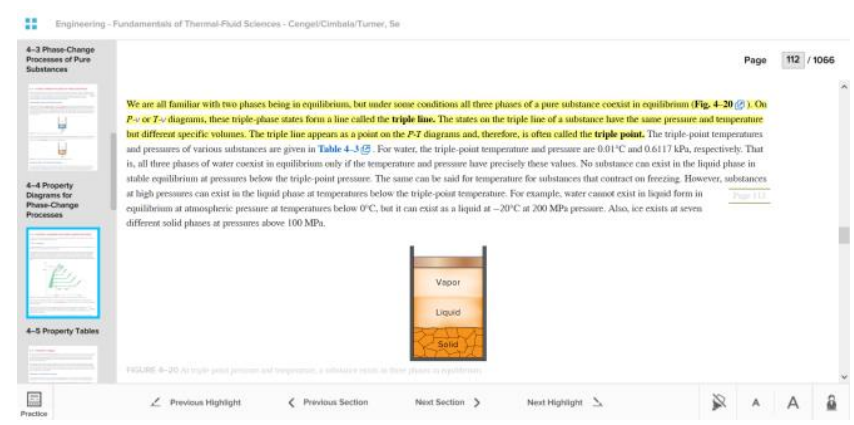

Fig. 3 The typical online text page of a reading assignment. As seen, the text which is deemed as important is highlighted. Students have an option of attempting the embedded questions by clicking on the 'Practice' icon. In order to quickly review important concepts, it is also possible to browse through just the highlighted text

The questions test the understanding of the reading material, and students are also asked about their confidence level. If a student is not sure how to answer a particular question, an option is provided to go back to the text, read the relevant text and come back to the question and attempt a different version of the question again. Thus, reading assignments can prove to be very useful to ensure that the students actually read the content and understand it. Moreover, the highlighted text makes it very easy for the students to review before exams and quizzes. As discussed earlier, this is also a very effective way of simulating the in-person student-instructor interactions during an in-person discussion regarding the student's doubts.
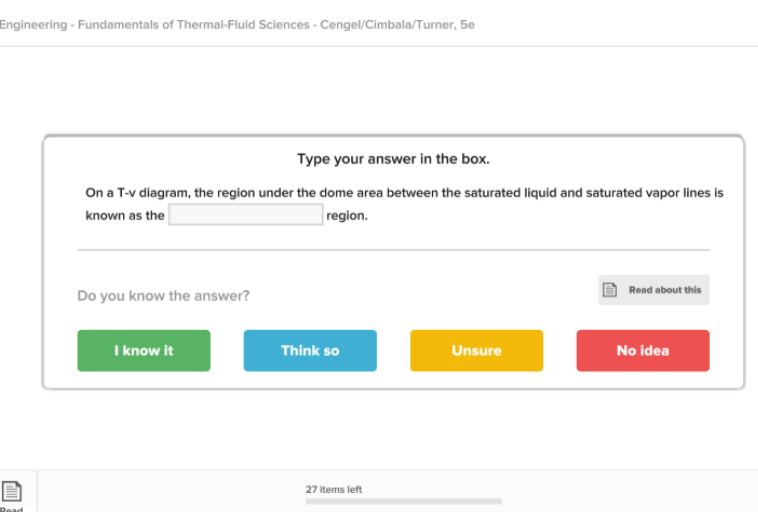

Fig. 4 A typical embedded question from a reading assignment. Along with the answer, students need to record the level of confidence as well Also, there is an option of jumping to the text relevant to the question. The progress in terms of the number of embedded questions left for completion of the reading assignment is also shown

\section{2) Homework Assignments:}

Homework assignments were also set as assignments, using a different set of policies than those for quizzes and exams. While exams and quizzes are designed to test the understanding of students, homework assignments are designed for students to study and practice the course material. Homework assignments and quizzes are held alternate week, and each homework is based on material covered two weeks prior to the homework deadline. Students are given a week to attempt all the questions in the homework assignment. Unlike quizzes, these questions are descriptive in nature. Thus, students upload their work as a document along with the default final values. While Connect grades the homework assignments based on the final answer values, the questions which the students incorrectly answer are graded manually based on the uploaded work as well, for partial credit. Often, pools of questions are used and the questions are algorithmic, just like quizzes and exams. The students have unlimited attempts for the homework assignments, as these are meant to be for practice purpose only. Connect also provides an option of giving hints to students for questions, through which students are presented with the relevant concepts which would help them arrive at the answer. This is very similar to how an instructor would guide a student with doubts in homework assignments.

\section{3) Quizzes:}

Quizzes are similar to exams, but of shorter duration and are more focussed on the content covered in the prior two weeks only, as opposed to exams which are significantly longer and based on cumulative syllabus. The default settings for quizzes are thus set to be quite similar to those of exams. Quizzes are typically designed to include only objective type questions like multiple choice questions, fill in the blanks, true or false etc., and the questions are so chosen/framed as to effectively judge the understanding of the students in a short period of time. 
The maximum time limit for the quizzes was 30 minutes, and two attempts were allowed for every quiz. Students were given a 6-hour window within which they were expected to complete both the attempts. It was observed that when multiple attempts were allowed, students simply copied the questions in the first attempt, worked out those specific questions or discussed those with their classmates and gave the second attempt. In order to avoid such situations, we now take average score of the two attempts, so that students take both the attempts sincerely. The feedback system was so designed that the students can right-away see their total score after every attempt, so that based on their score in the first attempt they can decide whether or not to attempt the quiz again. Detailed feedback, including solutions, is provided to the students 24 hours after the submission deadline.

Wherever possible, algorithmic questions were used, and the questions as well as options for multiple choice questions were scrambled. We also created pools of questions of similar difficulty level and the software drew a fixed number of random questions from this pool to create different permutations-combinations for different students. This essentially is an effective way to ensure minimum cheating and copying in an online course quiz, wherein physical proctoring is not possible.

\section{4) Exams:}

The exams were divided into two parts. Multiple choice questions were provided as part 1 , and detailed answer type worksheet questions were prepared as part 2. For the multiple choice questions, they were mostly conceptual questions and were helpful for covering wide range of knowledge points, as illustrated in Fig. 5.

\section{E connect}

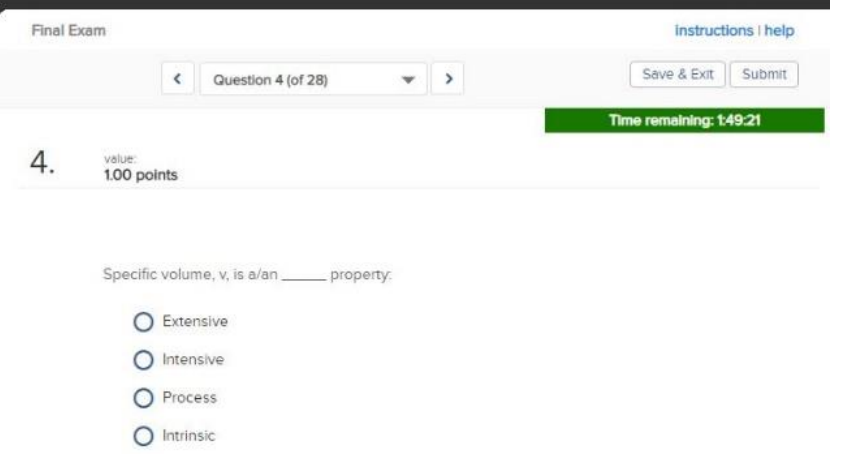

Fig. 5 Illustration of multiple choice questions part in Connect platform based exam

For preparing the multiple-choice part of the exam (which was typically $20 \%$ of the total exam weight), the instructor set up a question pool, for example, with 35 multiple choice questions, and then the Connect platform would randomly assign 25 of those questions to each student for guaranteeing each student's exam question was different. The multiple choice questions were partially chosen from online text and partially made by the instructor. From the realistic experience of using multiple choice questions in exam testing, it was found that multiple choice questions are a good way to test the fundamental conceptual understanding of the course materials for the students.

The worksheet or free-response questions, as illustrated in Fig. 6, were designed to be harder questions, and each question usually had multiple parts. The students were guided to resolve the problem by answering the questions from part to part. The Connect platform allowed the so called 'algorithmic questions' for the exam. For the algorithmic questions, the detailed numerical inputs for each question was assigned by Connect platform. As discussed earlier, it ensures that the question faced by each student has a different numerical value in the problems and thus has different correct answer, which provides a successful mechanism for cheating prevention in exams.

\section{: connect}
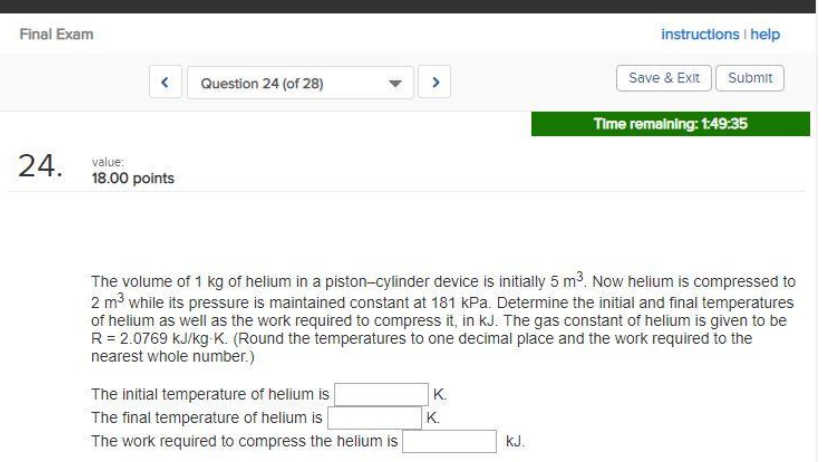

Fig. 6 Illustration of worksheet questions part in Connect platform based exam

For taking the Connect platform based online exam, a thirdparty proctoring service, Examity, is utilized in the exam for students that are not on campus. The exams were available within a given time period, for instance, 48 hours. Students were asked to choose a time slot on the proctoring service, and to take the online exam at that time. The students could also take on-campus exam at a given fixed time and location, but with the course instructor as proctor. To sum up, the students at a distance or on campus all use Connect platform for taking the exam, the only difference would be the proctoring process. The exams were set to be password protected and only one attempt was allowed. In the exams, students chose their best option for multiple choice questions and typed in the final answer for the worksheet questions in the answer box through the Connect platform. For the worksheet questions, the students were also asked to write down their solving process and upload two scanned figures as their problem solving work on the Connect platform.

For the exam grading, the multiple choice questions were graded automatically by Connect platform, while the worksheet questions were graded by the instructor and teaching assistants based on both the final answer provided and uploaded work. The corresponding exam policy set up needs to be specified with the Connect platform, as indicated in Fig. 7. The typical exam policies used are:

- The exam is password protected, 
- $\quad$ Printing of the exam is not allowed. For the automatic grading of answers, $<10 \%$ numeric tolerance is applied,

- Point assignment for each question is available to students,

- $\quad$ After the exam, a temporary score is immediately shown based on multiple question results and scores based on results of worksheet questions.

The feedback is held for 48 hours. After 48 hours, a report of the automatic graded scores and the correct solution is be available for the student.

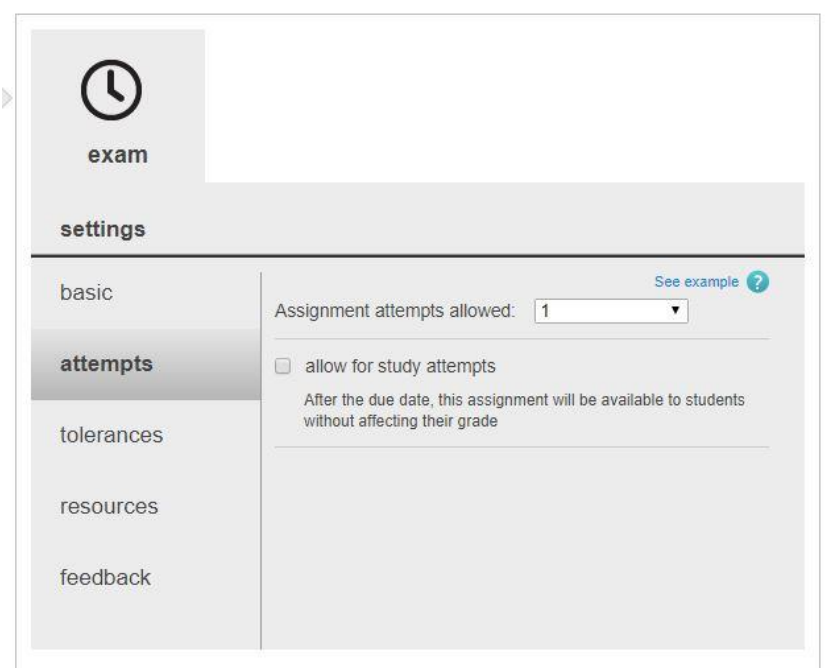

Fig. 7 Exam policy choosing system with Connect platform.

In addition, the instructor and/or teaching assistants would also carefully review the uploaded work of the problemsolution process and give the partial credit deserved. After the automatic grading and the instructor grading, the final scores were entered in the Connect platform. The Connect platform gives detailed post processed report for the exam, as shown in Fig. 8. In the post processed report, the scores are calculated, summarized, and analysed. The feedback includes the total scores, average score, and also the statistics for each problem. These statistics help the instructor to obtain direct information about how the students perform in each exam questions and understand the course materials as a direct and meaningful feedback.

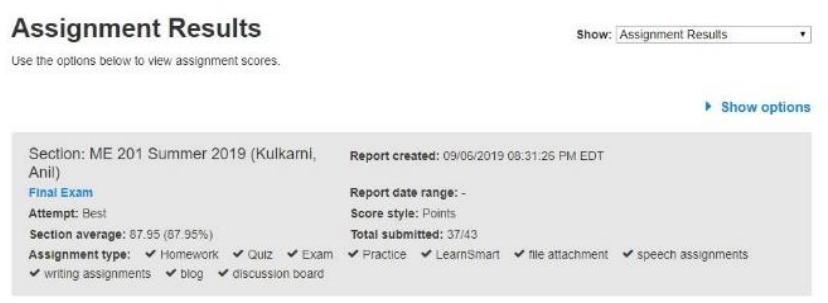

Fig. 8 Post processed report for the exam given by the Connect platform

\section{Students Feedback Regarding the Online Text Interface}

We obtained feedback from about 200 students who attended the online course in Spring and Summer 2019. Based on the students' comments on various aspects of the online text, we observed that overall, in their opinion, the Connect interface offers a more convenient and interactive way to efficiently read and review the material over the traditional textbookclassroom-blackboard methods. This was partly due to the specificity provided by the highlighted text. Also, students found it much easier to prepare for the exams, as all the data, such as solutions to the past quizzes and homework assignments etc., made the study process very organized and efficient. General sentiment of students was that the ability to take quizzes at the students' own convenient time and pace and the clarity about the assignment due dates etc. enhanced their course experience, as they did not have to worry about logistics and schedule of the course etc. A significant percentage of the overall comments also mentioned that the quiz and homework grading system becomes much fairer compared to most of the other college courses. While it is hard to untangle the exact role of various aspects, it is probably due to the transparency provided by the Connect platform, and the limited uncertainty and human error involved in manual grading of quizzes etc. In our opinion, the equality established by the process has led students to have more faith in the fact that their hard-work will pay off. This seems to have motivated most of them to put in more efforts into the learning process outside the class as well.

There were a few negative comments mostly by the students who preferred reading the text in the traditional, paper book over the online text. This concern can be addressed by purchasing or borrowing a print copy of the book along with the online text. Some students also found the reading assignments 'excessively long to read in entirety', and the highlighted text to be 'too disjoint'. However, as in any course, reading the text is an essential part of the learning process. Also, the highlighted text cannot replace the entire text and should be rather used simply as a tool for quick revision. Overall, we observed that the positive comments far outweigh the negative ones.

\section{Summary and Conclusions}

We present our experience of innovatively designing an online course on introductory thermo-fluid sciences on an electronic platform provided by McGraw Hill, - Connect online text [6] in addition to the commonly used LMS. The use of electronic book not only eased the efforts of instructors, teaching assistants and graders in terms of setting and grading the homework assignments, quizzes, exams and reading assignments, but also provided students with the flexibility to attempt the homework assignments at their pace. Various settings in the online text software enable the instructor to set the assignments in such a way that cheating and copying can be greatly reduced even in the absence of a proctor. Reading assignments on the online text platforms are very helpful in the learning process as well. Overall, the online text provides a more organized, efficient teachinglearning platform for conducting online courses as compared to the traditional methods. This is a one-of-its-kind 
online course conducting strategy which can potentially simulate in-class learning experience in a completely online course.

\section{References}

[1] Bourne, J., Harris, D., \& Mayadas, F. (2005). Online engineering education? Learning anywhere, anytime. Journal of Engineering Education, (January).

[2] London, J., \&Young, C. (2016). The Role of Massive Open Online Courses (MOOCs) in Engineering Education? Faculty Perspectives on its Potential and Suggested Research Directions. International Journal of Engineering Education, 32(4), 1788-1800.

[3] Yunus A. Çengel, Robert H. Turner, John M. Cimbala. (2001) Fundamentals of thermal-fluid sciences, Vol. 703. New York: McGraw-Hill.

[4] Cristy, John Oliver, and Joseph G. Tront. (2012) "The New E-textbook: Flipping the Page to the Next Paradigm." In American Society for Engineering Education. American Society for Engineering Education.

[5] Khalid A., Atiqullah M. M., Singh R., Stutzmann B. (2014). Text Books: eBooks or Print. In ASEE Annual Conference and Exposition, Conference Proceedings (Vol. 121, No. 121 st ASEE Annual Conference and Exposition.

[6] Wu, T. T., Shadiev, R., Huang, Y. M., \& Lai, C. F. (2015). An application of e-book system in embedded system course: Exploring learning effectiveness and behaviors. In ASEE Annual Conference and Exposition, Conference Proceedings (Vol. 122, No. 122nd ASEE Annual Conference and Exposition).

[7] Goodson, C.E., Miertschin, S.L. and Stewart, B.L. (2015). Design of on-line courses: Implications for student time management. The ASEE Computers in Education (CoED) Journal, 6(1), p.92.

[8] Kulkarni, A.K. and Iwinski, T. (2016). Enhancing Student Engagement in a Blended Resident and Online Course Using Clickers and Embedded Questions. Journal of Engineering Education Transformations, 30(1), pp.87-92.

[9] Berdanier, C.G., Tate, R.H., Iwinski, T. and Kulkarni, A. (2017). Investigation of engineering student engagement and behaviour in an online second-year thermal science course. Journal of Engineering Education Transformations, 30(3), pp.143-149.

[10] Chen, J., Victorino, C.A., Birdsong, C., Menon, U., Tseng, M. and Smith, T.S., (2011). A study of online textbook use across multiple engineering courses. In American Society for Engineering Education. American Society for Engineering Education. 